\title{
A DEFORMAÇÃO EM UMA ZONA DE CISALHAMENTO DESCONTÍNUA NA BORDA DO COMPLEXO METAMÓRFICO DO BAÇÃO, QUADRILÁTERO FERRÍFERO, MINAS GERAIS
}

\author{
CAROLINE J.S. GOMES* \& RONALDO S. EISELE*
}

\begin{abstract}
DEFORMATION OF A DISCONTINOUS SHEAR ZONE, BORDERING METAMORPHIC BACÃO COMPLEX, IRON QUADRANGLE, MINAS GERAIS. The west and northwest border of lhe Metamorphic Bação Complex constitute a shear zone of lhe strike-slip type, with small oblique movement. Composed of augen gneisses, protomylonitic to blastomylonitic, with compositional layering and high variation in lhe grain size, this shear zone suggests discontinous deformation. Characteristic are vertical to sub-vertical foliation, and stretched quartz and feldspar grains in a sub-horizontal position. Progressive deformation, mainly in a ductile shear style with a high magnitude of deformation was observed, which decreases during the transition to brittle shear. For interpretation of shear sense we used macroscopic and mesoscopic structures, i.e.: feldspar porphyroclast; asymmetrical folds of mylonitic foliation; dislocations of quartz veins; veins filling tension gashes; and, fractures of $\mathrm{P}$ and $\mathrm{Y}$ type showing slip. The statistics of these structures as well as field observations demonstrate a dominant sinistral slip, however a clock-wise movement hás accompanied every deformation phase in the studied shear zone.
\end{abstract}

Keywords: Metamorphic Bação Complex, strike-slip shear zone, tension gashes, dislocated quartz veins, shearsense history.

RESUMO A borda oeste e noroeste do Complexo Metamórfico do Bação, no Quadrilátero Ferrífero, Minas Gerais, constitui uma zona de cisalhamento do tipo transcorrente, com movimento levemente oblíquo. Esta zona é composta por augen-gnaisses, proto a blastomiloníticos, com bandamento composicional e variação granulométrica sugerindo deformação descontínua. A zona de cisalhamento estudada é caracterizada por uma foliação vertical a subvertical e lineações de estiramento de quartzo e feldspato, suborizontais. Registrou-se uma deformação progressiva com cisalhamento essencialmente dúctil e de alta magnitude de deformação que decresce durante a transição para a deformação rúptil. Para a definição do sentido de movimento, foram utilizadas estruturas macro e mesoscópicas, tais como: porfiroclastos de feldspato, dobras de arrasto, veios de quartzo tabulares deslocados, veios do tipo en echelon e fraturas Y e P com deslocamento. O levantamento estatístico dessas estruturas indica que domina o movimento sinistral, porém acompanhado por movimento dextral em todas as fases de deformação.

Palavras-chaves: Complexo Metamórfico do Bação, zona de cisalhamento transcorrente, fraturas en echelon, veios de quartzo deslocados, história do sentido de movimento.

INTRODUÇÃO Em trabalhos clássicos sobre a geologia do Quadrilátero Ferrífero, por exemplo, Dorr (1969) e Herz (1970), o Complexo Metamórfico do Bação é considerado de origem ígnea, intrusivo nas sequências metavulcânicas e metassedimentares do Supergrupo Rio das Velhas. Barbosa (1961), Guimarães et al. (1967), Drake \& Morgan (1980) e Souza Gomes (1985) descrevem um contato tectônico para o Complexo Metamórfico do Bação. Uma contribuição importante é dada por Gomes (1985), que, a partir de estudos petrológicos e geoquímicos nas rochas do complexo, interpreta os gnaisses como de origem metassedimentar.

Com base nesses estudos, o Complexo Metamórfico do Bação é hoje amplamente reconhecido como embasamento cristalino, que integra o Cráton São Francisco. Entre as inúmeras teorias já publicadas sobre o tectonismo que gerou o soerguimento do Complexo Metamórfico do Bação, algumas das mais importantes são:

- ascensão, num processo diapírico do tipo solid state (Barbosa 1968);

- tectonismo vertical de blocos do embasamento (Souza Gomes 1985, Alkmim et al. 1989);

- tectonismo compressional com formação de zonas de cisalhamento dúcteis, reversas, na borda oeste e sul do complexo onde se registra uma vergência das estruturas de leste para oeste (Marshak \& Alkmim 1989); e

- metamorphic core complex resultante de uma deformação extensional seguida por uma inversão tectônica (Chemale et al 1991).
A zona de cisalhamento na borda oeste e sudoeste do Complexo Metamórfico do Bação tem sido relacionada tanto a um evento tectônico puramente contracional, quanto a um evento de inversão tectônica com extensão no Proterozóico Inferior e compressão no Proterozóico Superior. A foliação milonítica invertida nos gnaisses e supracrustais sobrejacentes, no contato sudoeste do Complexo Metamórfico do Bação, e, em escala regional, o estrangulamento do Sinclinal da Moeda na sua porção sul próximo à junção com o Sinclinal Dom Bosco sugerem cavalgamentos nessa região. Entretanto, uma análise estrutural cuidadosa efetuada na zona de cisalhamento da borda oeste e noroeste do Complexo Metamórfico do Bação revela movimentos horizontais, transcorrentes, em regime de deformação dúctil até rúptil.

O objetivo deste trabalho é estudar a cinemática da zona de cisalhamento da borda oeste e noroeste do Complexo Metamórfico do Bação (Fig. 1), por meio do levantamento sistemático das macro e microestruturas.

A ZONA DE CISALHAMENTO DÚCTIL NA BORDA OESTE E NOROESTE DO COMPLEXO METAMÓRFICO DO BAÇÃO As rochas do Complexo Metamórfico do Bação compõem-se de gnaisses e migmatitos polimetamórficos de composição tonalítica-trondjemítica a granodiorítica (Gomes 1985). Em toda extensão de sua borda, ocorrem augen-gnaisses protomiloníticos a miloní- 


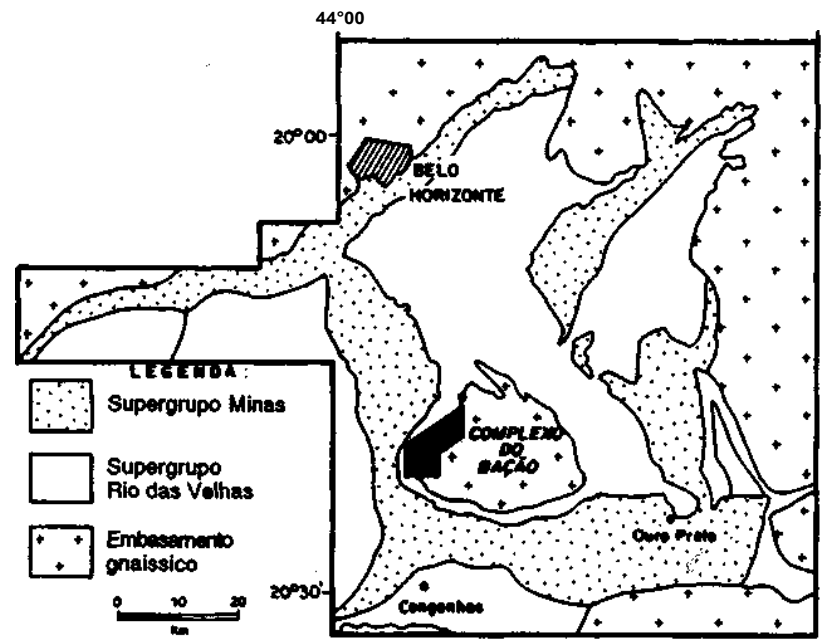

Figura 1 - Mapa geológico simplificado do Quadrilátero Ferrífero (modificado de Dorr 1969) e localização da área estudada

Figure 1 - Simplified geological map of the Iron Quadrangle (modified from Dorr 1969) and location of the studied area

ticos, localmente cortados por migmatitos, e uma foliação milonítica paralela ao contato nos gnaisses e nas supracrustais.

A zona de cisalhamento da borda oeste e noroeste do Complexo Metamórfico do Bação constitui uma faixa de aproximadamente $1.000 \mathrm{~m}$ de largura. Nessa área, as rochas compõem-se essencialmente de quartzo, feldspato potássico, plagioclásio e biotita e, secundariamente, de muscovita, epídoto/clinozoísita, titanita e zirconita. Uma intensa recristalização dinâmica de quartzo e feldspato e a ausência de feições rúpteis nos porfi rociastes de feldspato examinados sob o microscópio sugerem condições de pressão e temperatura elevadas durante a deformação. As rochas constituem tectonitos S-L com foliação subvertical e lineações de estiramento de cristais de quartzo e feldspato suborizontais, sempre paralelas ao contato (Fig. 2).

A foliação principal das rochas é proto a blastomilonítica e coincide com o bandamento composicional. Sob o microscópio, a foliação é definida pela orientação planar de cristais de biotita e agregados alongados de quartzo e feldspato.
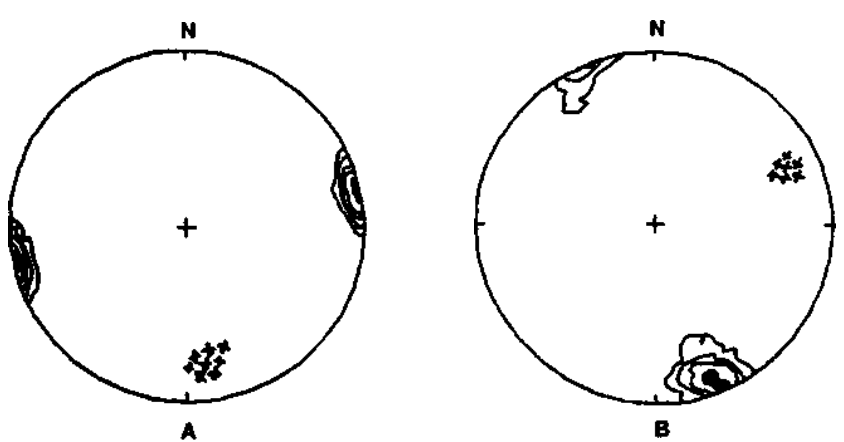

Figura 2 - Diagramas de igual área, hemisfério sul, para pólos da foliação milonítica (contornos a 5, 10, 20, 30 e $40 \%)$ e para poios da lineação de estiramento mineral (cruzinhas):(A) da borda oeste e (B) da borda noroeste do Complexo Metamórfico do Bação

Figure 2 - Lower hemisphere, equal-area nets showing mylonitic foliation poles (contours at $05,10,20,30$ e $40 \%$ ) and stretched mineral lineation poles (crosses): (A) from the west border and (B) from the northwest border of the Metamorphic Bação Complex
Em escala de afloramento, a deformação é heterogênea, pois faixas intensamente cisalhadas alternam corn porções menos deformadas. Estas são caracterizadas por foliações conjugadas S-C e por porfiroclastos de feldspato assimétricos de 0,3 a $3,0 \mathrm{~cm}$ de comprimento. Nas porções mais deformadas, a foliação $\mathrm{S}$ se paraleliza com as bordas da zona de cisalhamento, devido a uma rotação durante o movimento (Ramsay \& Huber 1987).

ANÁLISE CINEMÁTICA Na zona de cisalhamento estudada, os principais indicadores cinemáticos são porfiroclastos de feldspato, oblíquos em relação à foliação milonítica, comumente com sombras de pressão assimétricas, e dobras de arrasto.

O levantamento sistemático do sentido de movimento, a partir dos porfiroclastos de feldspato, revelou que predomina o sentido anti-horário, porém um movimento horário também é registrado. A ocorrência de movimentos conflitantes é, segundo Bell \& Johnson (1992), comum em uma zona de cisalhamento dúctil.

As dobras de arrasto da foliacão milonítica refletem essencialmente movimento sinistral. Às vezes ocorrem zonas de cisalhamento dúcteis, oblíquas em relação à foliação milonítica dos augen-gnaisses, estas com movimento claramente dextral (Fig. 3). Uma relação genética com a zona de movimentação principal não foi observada.

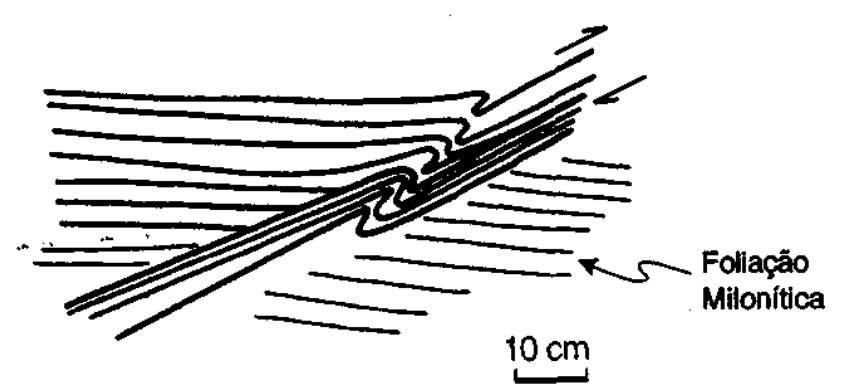

Figura 3 - Zona de cisalhamento dúctil, discordante e dextral

Figure 3 - Discordant dextral ductile shear zone

Para uma definição segura da cinemática na borda oeste e noroeste do Complexo Metamórfico do Bação, procuraram-se critérios macroscópicos complementares. Identificou-se o sentido de movimento em estruturas dúcteis-rúpteis (veios en echelon), rúpteis-dúcteis (veios de quartzo tabulares, deslocados) e rúpteis (fraturas Riedel, anti-Riedel, Y e P; Hancock 1985).

Veios de quartzo, tabulares, normais à foliação milonítica dos augen-gnaisses, ocorrem com frequência na borda oeste e noroeste do Complexo Metamórfico do Bação. Possuem espessura centimétrica a decimétrica e, apesar de representarem fase deformacional mais nova, são deslocados ductilmente ao longo da foliação (Fig. 4), sempre no sentido anti-horário.

Em um grande afloramento de augen-gnaisses, na borda noroeste do Complexo Metamórfico do Bação, no Córrego do Bação, ocorrem fraturas de extensão do tipo en echelon. São preenchidas por veios de quartzo, de granulação gros$\mathrm{sa}$, e turmalina, e ocorrem em várias faixas, de 2 a $3 \mathrm{~m}$ de largura, sempre paralelas à foliação milonítica da rocha encaixante. Os veios, apesar de perpendiculares à foliação, exibem feições de rotação sob um regime dúctil-rúptil. Além disso, esses veios são, às vezes, cortados pela própria foliação milonítica do augen-gnaisse e, nesse caso, deslocados no sentido anti-horário. O movimento tardio, ao longo da foliação milonítica, como também constatado para os 
veios tabulares, sugere que a zona de cisalhamento desenvolveu-se por uma deformação progressiva.

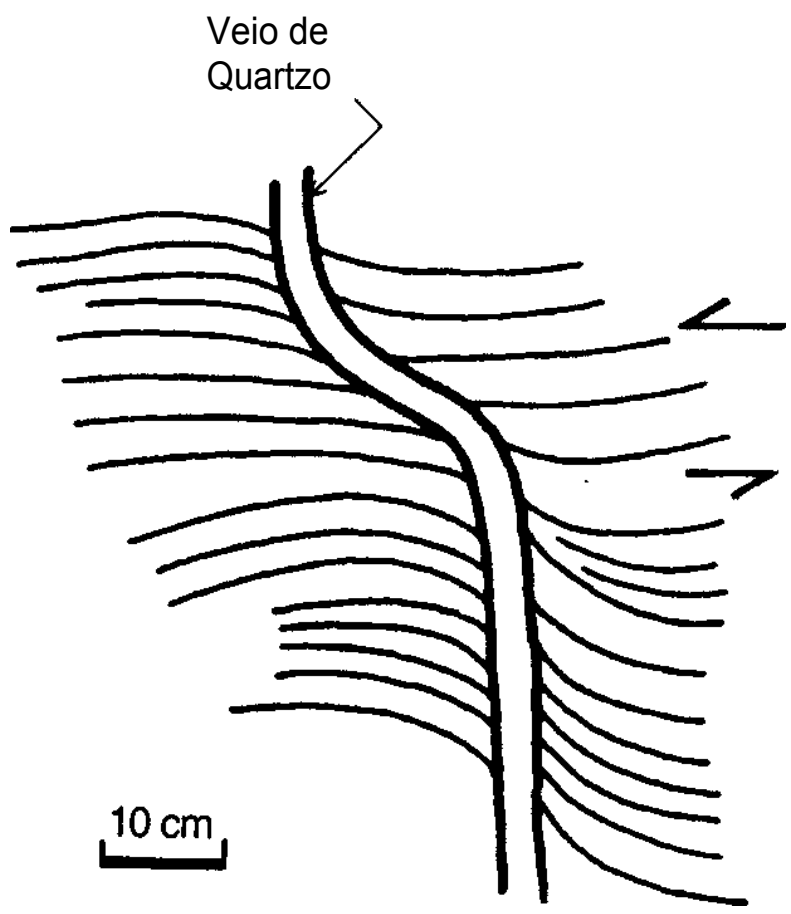

Figura 4 - Veio de quartzo tabular deslocado ao longo da foliação milonííica, em um estágio tardio da deformação dúctil

Figure 4 - Tabular quartz vein dislocated parallel to the mylonitic foliation by a later stage of ductile deformation

As fraturas de extensão em geral não apresentam a forma sigmoidal típica de veios en echelon com terminações a $45^{\circ}$ das bordas da zona de cisalhamento ou novas fraturas nessa posição. No entanto, registra-se com frequência um deslocamento ou arrasto da foliação milonítica ao longo das paredes externas dos veios (Fig. 5). Esse arrasto sugere abertura oblíqua das fraturas, como consequência de uma deforma-
A

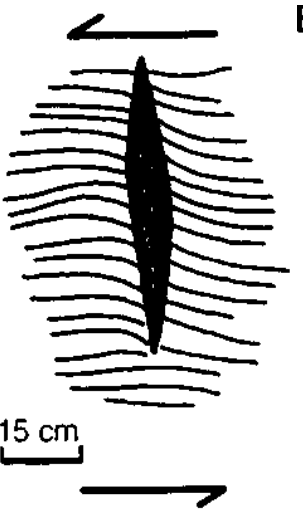

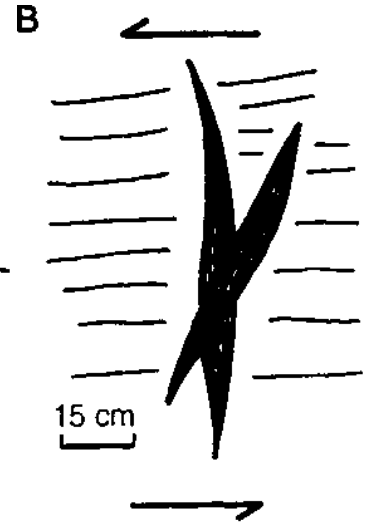

Figura 5 - Feições de rotação em veios que compõem os sistemas de fraturas en echelon: A. Arrasto dextral da foliação milonítica nas paredes do veio. $\boldsymbol{B}$. Veios se interceptando (muito raros); observa-se que o mais antigo sofreu rotação anti-horária enquanto o mais novo ocupa a posição da direção de maior encurtamento Figure 5 - Rotation features in veins of en-echelon tension gash systems: A. Dextral offset of mylonitic foliation at wall of vein. B. Intercepting veins (extremely rare), demonstrate a counter-clock-wise rotation experienced by the oldest vein; while the younger vein demonstrates its long axis parallel to the direction of major shortening cão não-coaxial. McClay (1976, in Hudleston 1989) demonstrou experimentalmente, com plasticina, o desenvolvimento progressivo desse tipo de estruturas.

O levantamento sistemático de todas as juntas de extensão, nessa área, forneceu as rosetas da figura 6. Observa-se que $25 \%$ das fraturas apresentam abertura oblíqua dextral e, apenas $10 \%$, uma abertura sinistral.

A figura 7 mostra que a abertura dextral corresponde a um movimento anti-horário da zona de cisalhamento.

Tanto os veios en echelon quanto os veios tabulares foram cortados e deslocados por fraturas mais novas, Y, subparalelas à foliação. $\mathrm{O}$ deslocamento ocorre, ora em regime rúptil-dúctil com pequeno arrasto dúctil (Figs. $8 \mathrm{~A} \mathrm{e}$ B), ora completamente rúptil (Figs. 9 A e B).

Identificaram-se, ainda, fraturas $\mathrm{P}$ que cortam em ângulo agudo a foliação, gerando pequenas dobras de arrasto (Fig. $10)$.
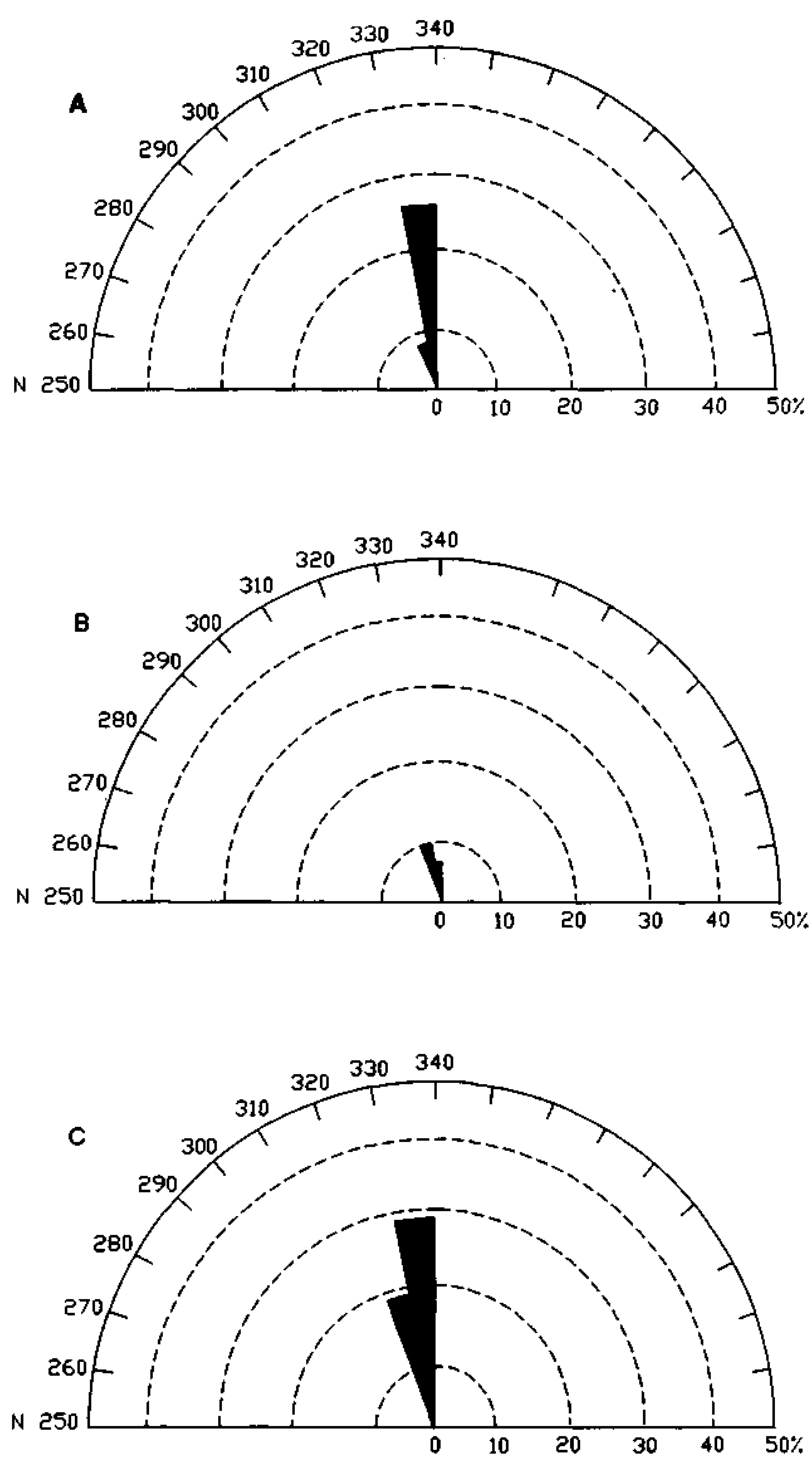

Figura 6 - Rosetas das juntas de extensão preenchidas por quartzo $(n=70)$. A. Juntas de extensão com abertura obliqua dextral; B. Juntas de extensão com abertura oblíqua sinistral; $\boldsymbol{C}$. Juntas de extensão com abertura normal às paredes dos veios

Figure 6 - Rose diagrams of extension fractures filled by quartz $(n=70)$. A. Extension fractures with dextral oblique opening; B. Extension fractures with sinistral oblique opening; C. Extension fractures with normal opening of fracture wall 


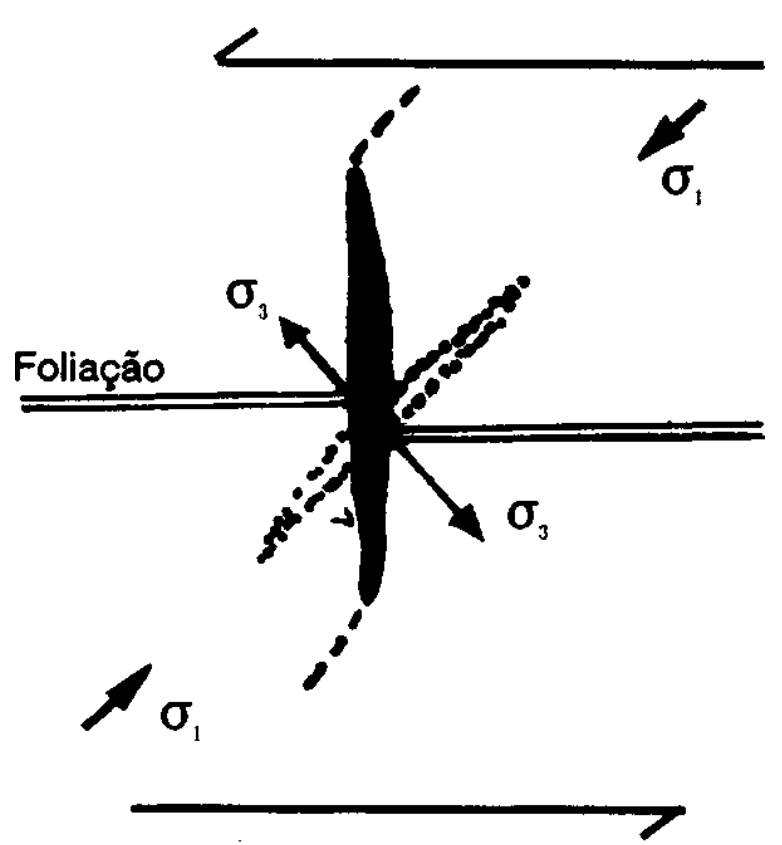

Figura 7 - Representação esquemática de um par cisalhante sinistral com asfraturas de extensão e a orientação das tensões principais máxima $\left(\sigma_{1}\right)$ e mínima $\left(\sigma_{3}\right)$ A fratura mais antiga sofreu rotação e durante a nucleação da mais nova, $\left(\sigma_{3}\right)$ gera abertura oblíqua na primeira

Figure 7 - Schematic representation of a sinistral shear pair with extension fractures and the orientition of $\left(\sigma_{1}\right)$ maximum and $\left(\sigma_{3}\right)$ minimum principal stresses. The older fracture had been rotated and when the younger fracture formed, $\left(\sigma_{3}\right)$ generated an oblique opening in the former
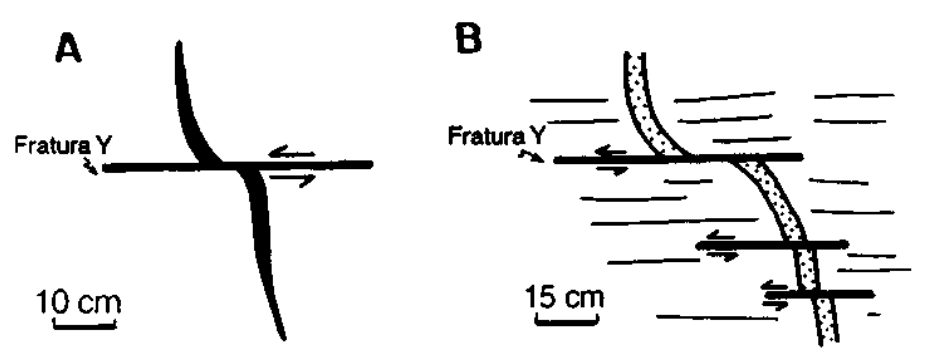

Figura 8 - Deslocamento rúptil-dúctil: $\boldsymbol{A}$. Um veio do sistema en echelon. B. Um veio tabular

Figure 8 - Brittle-ductile offset: A. One vein of en echelon system. B. One tabular vein

A análise das rosetas das juntas que cortam os veios (juntas "pós-veios" na Fig. 11) revela que ao longo das fraturas $\mathrm{Y}$ e $\mathrm{P}$ pode ocorrer movimento dextral, mas, estatisticamente, domina o deslocamento sinistral.

Na zona de cisalhamento em estudo, observam-se, ainda, esporádicas faixas, de espessura centimétricas, paralelas à foliação, que exibem pequenas falhas de compressão e brechas.

DISCUSSÃO E CONCLUSÃO A análise da zona de cisalhamento da borda oeste e noroeste do Complexo Meta-
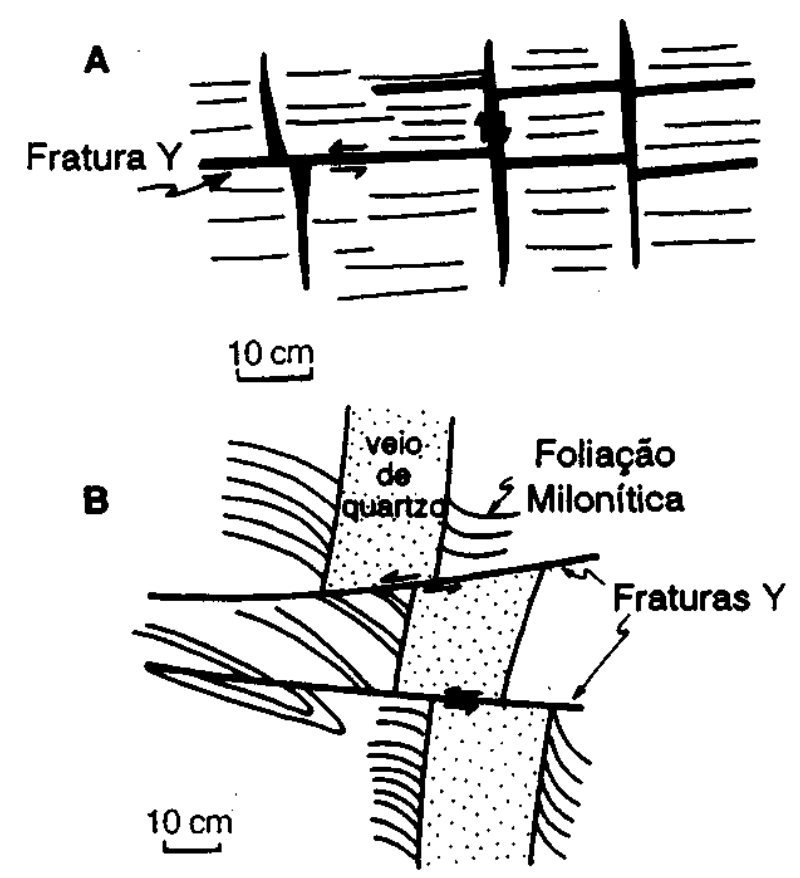

Figura 9 - Deslocamento rúptil: A. Sistema de veios en echelon. B. Um veio tabular

Figure 9 - Brittle dislocation: A. En echelon system of veins. B. One tabular vein

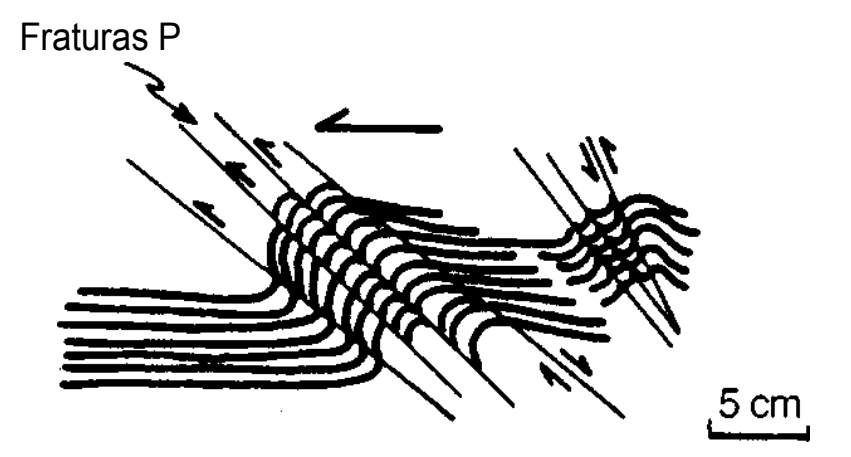

Figura 10 - Fraturas P deslocam a foliação milonítica gerando pequenas dobras

Figure 10 - $\mathrm{P}$ fractures dislocating mylonitic foliation forming folds

mórfico do Bação revelou a presença de indicadores cinemáticos dúcteis, dúcteis-rúpteis, rúpteis-dúcteis e rúpteis, todos possuindo relação com um mesmo evento deformacional.

$\mathrm{O}$ cálculo da deformação finita nos augen-gnaisses da área de trabalho, a partir de cristais estirados de quartzo (Souza Gomes 1993), revelou alta magnitude de deformação, com valores máximos de $R_{x z}=17: 1$ e $E_{s}=2,02$. Já, o pequeno rejeito dos veios de quartzo ao longo das fraturas $\mathrm{Y}$ e $\mathrm{P}$, centimétrico a decimétrico, caracteriza uma baixa magnitude de deformação para o cisalhamento rúptil.

As lineações de estiramento de quartzo e feldspato sobre a foliação milonítica dos augen-gnaisses, suborizontais, demonstram que a borda oeste e noroeste do Complexo 

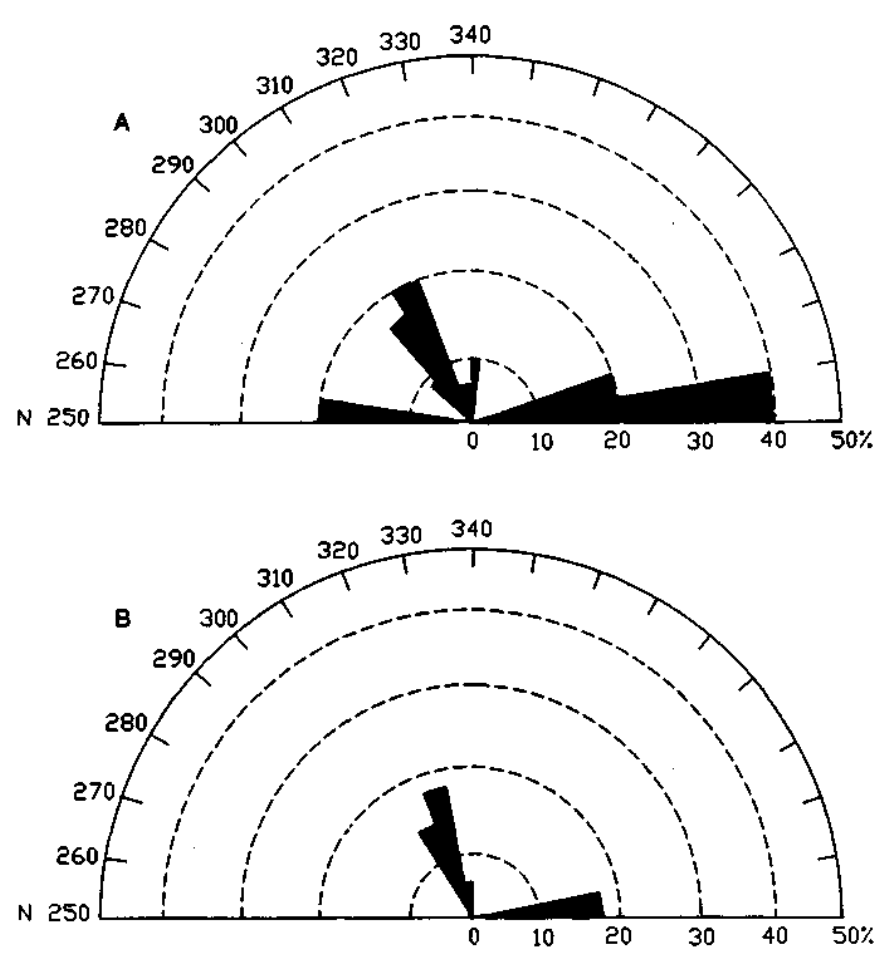

Figura 11 - Rosetas de juntas "pós-veios" ( $\mathrm{n}=80)$. $\boldsymbol{A}$. Juntas com deslocamento sinistral. B. Juntas com deslocamento dextral

Figure 11 - Rose diagrams of "post-vein" fractures $(n=80)$. A. Fractures with sinistral dislocation. B. Fractures with dextral dislocation

Metamórfico do Bação constitui uma zona de cisalhamento transcorrente com movimento levemente oblíquo. Em outros complexos do embasamento, do Quadrilátero Ferrífero, não ocorrem contatos transcorrentes, registrando-se nestes a presença de feições extensionais e ou compressionais. A cinemática direcional na área de trabalho constitui, por enquanto, uma incógnita na história evolutiva do Quadrilátero Ferrífero.

Propõe-se, para a zona de cisalhamento, progressiva e de magnitude de deformação decrescente, da borda oeste e noroeste do Complexo Metamórfico do Bação, a seguinte evolução:

1. Cisalhamento dúctil a. Desenvolvimento da foliação milonítica e concomitante estiramento de minerais e formação de porfiroclastos de feldspato; geração de dobras de arrasto.

b. Fraturamento hidráulico e preenchimento por soluções ricas em sílica, dando origem a veios de quartzo tabulares. c. Deslocamento dúctil dos veios de quartzo, paralelamente à foliação milonítica.

2. Cisalhamento dúctil-rúptil Geração e preenchimento de fraturas de extensão do tipo en echelon.

3. Cisalhamento rúptil-dúctil Desenvolvimento de fraturas $\mathrm{Y}$ e $\mathrm{P}$ e deslocamento rúptil-dúctil dos veios de quartzo.

4. Cisalhamento rúptil Deslocamento rúptil dos veios de quartzo e, em pequena escala, geração de brechas.

A análise cuidadosa dos indicadores cinemáticos demonstrou que movimentos conflitantes não ocorrem apenas durante a deformação dúctil, mas em todas as etapas da deformação. Conclui-se que o sentido de movimento é predominantemente sinistral e um movimento contrário, dextral, acompanhou secundariamente todas as fases.

Agradecimentos Os autores desejam externar agradecimentos ao Conselho Nacional de Desenvolvimento Científico e Tecnológico pelo apoio financeiro fornecido através da concessão de Bolsa de Pesquisa e de Bolsa de Iniciação Científica.

\section{REFERÊNCIAS BIBLIOGRÁFICAS}

BARBOSA, A.L.M. 1961. Tectônica do Quadrilátero Ferrífero de Minas Gerais. Bol SICEG 1:49-54.

BARBOSA, A.L.M. 1968. Contribuicões Recentes à Geologia do Quadrilátero Ferrifero. Ouro Preto, EM-UFOP/SBG-NMG. 63 p.

BELL, T.H. \& JOHNSON, S.E. 1992. Shear sense: a new approach that resolves conflicts between criteria in metamorphic rocks. J. Metamorph. Geol., 10:99-124.

CHEMALE, F.; ROS1ÉRE, C.A.; ENDO, I. 1991. Evolução tectônica do Quadrilátero Ferrífero, Minas Gerais - Um modelo. Pesquisas, 18(2): $104-127$.

DORR, J.V.N. 1969. Pliysiograplnc, Stratigraphic and Structural Development of the Ouadrilatero Ferrifero, Brazil. Washington, U. S. Geol. Survey. 110 p. (Prof. Paper 641-A)

DRAKE, A. \& MORGAN, B.A. 1980. Precainbrian Plate Tectonics in the Brasilian Shield - Evidence from the Pré-Minas Rocks of the Quadrilátero Ferrifero, Minas Gerais. Washington, U. S. Geol. Survey. 19 p. (Prof. Paper 1119-B).

GOMES, M.S. 1985. Petrologisclie - Geochemische Untersuchungen in Bação - Komplex, Eisernes Viereck, Minas Gerais, Brasilien. Clausthal - Zeller feld. 209 p. (Tese de Doutoramento).

GUIMARÃES, D.; MELO, S.M.; MELO, E.A.V. 1967. O Complexo de Bacão. Bol. $1 G / E M / U F O P .2: 1-12$.

HANCOCK, P.L. 1985. Brittle microtectonics: principies and practice. $J$. Sintct. Geol., 7(3/4):437-457.
HERZ, N. 1970. Gneissic and Igneous Rocks of the Quadrilatero Ferrifero, Minas Gerais, Braiil. Washington, U. S. Geol. Survey. 58 p. (Prof. Paper 641-B)

HUDLESTON, P.J. 1989. The association of folds and veins in shear zones. J. Struct. Geol., II(8):949-957.

MARSHAK, S. \& ALKMIM, F.F. 1989. Proterozoic contraction/extension tectonics of the southern São Francisco region, Minas Gerais. Brazil. Tectonics, 8(3):555-571.

RAMSAY, J.G. \& HUBER, M.I. 1987. The Techniques of Modern Structural Geology. 2 v. London. Acad. Press. 700 p.

SOUZA GOMES, C.J.S. 1985. Strukturelle und Texturelle Untersuchungen im Bação-Komplex und Seinen Rahmengesteinen, Eisernes Viereck, Minas Gerais, Brasilien. Clausthal - Zellerfeld. 190 p. (Tese de Doutorado, T.U. Clausthal).

SOUZA GOMES, C.J.S. 1993. The west and northwest border of the Bação Complex: strain and microstructures. Zbl. Geol. Paläont., 7/8:797-806. (Teil 1).
MANUSCRITO A767 Recebido em 30 de marco de 1993 Revisão do autor em 12 de maio de 1993 Revisão aceita em 21 de maio de 1993 